\title{
Comparison of Ultrasound-Guided Femoral and Infrapatellar Nerve Block Effects after Anterior Cruciate Ligament Repair Surgery
} \author{
Reza Faiz1,* \\ ${ }_{1}$ MD, Professor, Department of Anesthesia, Rasool Akram Medical Complex, Iran University of Medical Sciences, Tehran, Iran \\ 2 MD, Assistant Professor, Department of Anesthesia, School of Medicine, Iran University of Medical Sciences, Tehran, Iran \\ ${ }^{3}$ MD, Associate Professor, Department of Anesthesia, School of Medicine, Iran University of Medical Sciences, Tehran, Iran \\ ${ }^{4}$ MD, Professor, Department of Anesthesia, Pain Research Center, Iran University of Medical Sciences, Tehran, Iran \\ 5 MD, Resident Student, Department of Anesthesia, School of Medicine, Iran University of Medical Sciences, Tehran, Iran
}

Poupak Rahimzadeh ${ }^{1}$, Salome Sehat Kashani ${ }^{2}$, Karim Hemati ${ }^{3}$, Farnad Imani $^{4}$, AkramSalimi ${ }^{5}$ and Seyed Hamid

* Corresponding author: Seyed Hamid Reza Faiz, Department of Anesthesia, School of Medicine, Iran University of Medical Sciences, Tehran, Iran. Tel: +989121534811, +9802164352326; Email: Shr.faiz.anesthesiology@gmail.com, hrfaiz@hotmail.com

Received 2020 0ctober 09; Revised 2020 November 01; Accepted 2020 November 10.

\begin{abstract}
Background: There are various protocols for pain management after anterior cruciate ligament (ACL) reconstruction surgery.

Objectives: This study aimed to compare two blocking protocols, including femoral nerve block (FNB) and infrapatellar nerve block (IPNB) in terms of pain severity, patient satisfaction, and muscle force preservation.

Methods: This single-blind clinical trial study investigated the patients who underwent elective knee arthroscopic ACL surgery randomly either by ultrasound-guided FNB or IPNB. Subsequently, the patients were evaluated 1, 3, 6, 12, and $24 \mathrm{~h}$ following NB for pain severity, patient satisfaction level, and muscle force.

Results: The pain score (both at rest and in flexion) was significantly lower in the first three $\mathrm{h}$ after the intervention in the FNB group. Moreover, the mean score of the patients' satisfaction in the first hours was significantly higher in the FNB group after the procedure. Additionally, the IPNB group obtained a significantly faster mean time required for the first dose of opioid request. The mean dose of used opioids over $24 \mathrm{~h}$ was significantly lower in the FNB group. There was a significant difference between the groups in terms of the muscle strength score within $24 \mathrm{~h}$; moreover, the FNB group obtained a significantly greater delay in muscle recovery.

Conclusion: The FNB is associated with greater pain relief and satisfaction in patients who underwent arthroscopic ACL reconstruction surgery, compared to the IFNB technique. However, a further delay in the recovery of quadriceps muscle force is evident in the FNB group.
\end{abstract}

Keywords: ACL reconstruction, Femoral nerve block, Infrapatellar nerve block, Postoperative pain management, Ultrasound

\section{Background}

Despite the minimally-invasive nature of knee arthroscopic surgery, compared to traditional surgical methods, postoperative pain in these patients may be significantly high. These patients sometimes require high doses of opioids $(1,2)$. Furthermore, after the utilization of such medications, there will be a possibility of some complications, such as respiratory depression, nausea, and vomiting. Peripheral nerve blocks have shown high efficiency and can decrease the requirement for opioids administration (3-6). It is worth mentioning that adequate postoperative pain relief is a significant factor in the early ambulation and rehabilitation of patients after knee surgery (7).

Lower extremity innervation has arisen from the lumbar and lumbosacral plexus. The lumbar plexus is normally formed by L1-L4 roots and occasionally by branches of T12 or L5 $(8,9)$. The femoral nerve is composed of L2, L3, and L4 branches, which are the largest and most significant branches of the lumbar plexus (9). The femoral nerve block (FNB) is an easy technique with low side effects. This method has been followed for anterior leg surgeries and pain management after pelvic and knee surgeries (10).

The anterior cruciate ligament (ACL) reconstruction surgery can cause the weakness of the quadriceps muscle mainly due to reflex inhibition which is secondary to joint effusion, or the pain that prevents the easy movement of the knee joint $(11,12)$. The preservation of the strength of quadriceps muscles is the aim of post-operative rehabilitation and a significant factor that decides about the return of the affected person to daily activities and professional performance after ACL reconstruction surgery (12-14).

Despite the high efficiency of FNB in decreasing the pain intensity after the knee surgery, it has led to some complications, such as quadriceps weakness (15-23). Multiple methods have been surveyed for pain control after ACL reconstruction, such as multimodal analgesia, intra-articular injection of morphine, and sciatic nerve block (24-29). However, FNB is still the method that is mostly used due to its simplicity and effectiveness.

\section{Objectives}

This study aimed to compare the femoral and 
infrapatellar nerve block effects in terms of pain score, quadriceps force, and satisfaction after the performance of these two techniques. It should be mentioned that the infrapatellar nerve is a sensory nerve and one of the terminal branching of the femoral nerve.

\section{Methods}

This single-blind clinical trial was performed on patients who were candidates for elective arthroscopy ACL surgery and referred to Rasoul Akram Hospital, Tehran, Iran, during 2019. The study protocol was approved by the Ethical Committee of Iran University, Tehran, Iran (IR.IUMS.FMD.REC. 1398.377) and registered in the Iranian Registry of Clinical Trials (IRCT20120814010599N22). The inclusion criteria were: 1) age range between 20 and 45 years, 2) physical status of I-II according to American Society of Anesthesiologists classification, and 3) patients' willingness.

The primary outcome variable in this study is the pain score (classified from 0-10), and more than a 2point decrease in this score is considered clinically significant. Moreover, the confidence and power levels in this study were $95 \%$ and $80 \%$, respectively. Considering the sample attrition, the minimum number of patients in each group was estimated at 46 cases.

On the other hand, the patients with coagulation disorders, infection at the injection site, neurological disorders, neuropathies at the site of the operation, sensitivity to local anesthetics, drug addiction, liver or kidney failure, and body mass index (BMI) $\geq 35$ were excluded from the study.

Pulse oximetry, electrocardiography process, and non-invasive blood pressure measurement of the patients were controlled upon entering the operating room, and they were then hydrated with Ringer's lactate solution. Subsequently, the spinal anesthesia at the L4-L5 level was conducted in the lateral position using a 25-gauge needle containing $3 \mathrm{cc}$ bupivacaine $0.5 \%$.

Following the surgery with regression of at least three dermatomes from the spinal block, the patients were assigned to ultrasound-guided FNB or infrapatellar nerve block (IPNB) groups using a computer-generated random sequence. Afterward, the area was prepared for the FNB, and the linear ultrasound probe was located over the inguinal ligament in a short-axis view. In the next stage, the femoral nerve was placed lateral to the femoral artery below the iliac fascia. A 5-7 cm acoustic needle was inserted in-plane from the outside of the artery and directed toward the femoral nerve, followed by the perineural injection using $15 \mathrm{cc}$ of ropivacaine $0.2 \%$.

The patients' thighs in the IPNB group were placed at an external rotation. The linear ultrasound probe was positioned in a short-axis view in mid-thigh exactly medial to the sartorius muscle. In this position, the saphenous nerve is more superficial than the femoral artery. After the saphenous nerve was observed, it was moved more distally to determine the infrapatellar nerve being isolated ( 1 to $2 \mathrm{~cm}$ lower the saphenous nerve). Furthermore, an injection was made using a $5-7 \mathrm{~cm}$ sonovisible needle containing $15 \mathrm{cc}$ of ropivacaine $0.2 \%$.

Patient-controlled intravenous analgesic pump containing $10 \mathrm{cc}$ of fentanyl in $100 \mathrm{cc}$ normal saline was connected to continuous flow amount of $2 \mathrm{cc} / \mathrm{h}$ with a lockout interval of $15 \mathrm{~min}$ in both groups. The first drug request and the overall drug dose was calculated in $24 \mathrm{~h}$. Patients were evaluated in recovery, as well as at $1,3,6,12$, and $24 \mathrm{~h}$ after surgery in terms of pain intensity at rest and knee flexion according to a visual analog scale (VAS), satisfaction level according to a 5-point Likert scale (strongly satisfied=5, strongly dissatisfied $=1$ ), and muscle force grading (no contraction=grade 0 , normal=grade 5 ). The evaluation was conducted by one of the authors who was blind to the patient grouping.

\subsection{Statistical Analysis}

The data were analyzed using SPSS software (version 22) through the Kolmogorov-Smirnov test to determine the normality of quantitative variables. Furthermore, the quantitative and qualitative variables were assessed using the t-independent or Mann-Whitney-U test and chi-square or Fisher's exact test, respectively. A p-value less than 0.05 was considered statistically significant.

\section{Results}

This study included 92 patients who were referred to Rasoul Akram Hospital, Tehran, Iran, for elective ACL surgery. The patients were assigned to the IPNB $(n=46)$ and FNB groups $(n=46)$. Figure 1 illustrates the consort flow chart.

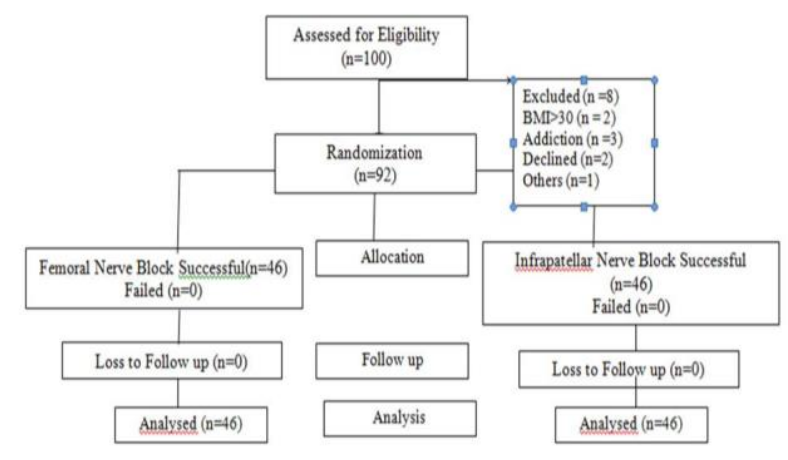

Figure 1. CONSORT flowchart 
According to the results, there was no significant difference between the two groups regarding age, gender, BMI, and duration of surgery $(\mathrm{P}>0.05)$ (Table 1). The mean VAS scores at rest, 1 and, $3 \mathrm{~h}$ was significantly lower in the FNB group, compared to those in the IPNB group $(\mathrm{P}<0.05)$ (Table 2$)$.

Moreover, the evaluation of pain score at rest using repeated ANOVA showed no significant difference between groups regarding the next $24 \mathrm{~h}$ after the NB ( $\mathrm{P}=0.082)$. No significant difference was also observed between the two groups in terms of the mean VAS scores in flexion during recovery times, as well as 3, 6, 12, and $24 \mathrm{~h}$ after NB ( $>>0.05)$. Flexion pain scores $1 \mathrm{~h}$ after $\mathrm{NB}$ in the FNB group was significantly lower, compared to those in the IPNB group $(\mathrm{P}<0.05)$ (Table 3$)$.
Additionally, the evaluation of pain score trends during flexion using repeated ANOVA revealed a significant difference between the groups in terms of the next $24 \mathrm{~h}$ after $\mathrm{NB}(\mathrm{P}=0.004)$.

The mean satisfaction score one $\mathrm{h}$ after the block in the FNB group was significantly higher than that in the IPNB group $(\mathrm{P}<0.05)$. At other times, there was a significant difference between the two groups in this regard $(\mathrm{P}>0.05)$ (Table 4$)$.

Similarly, the results of repeated ANOVA regarding the evaluation of satisfaction score trends indicated a significant difference between the two groups in terms of the next $24 \mathrm{~h}$ after the NB ( $\mathrm{P}=0.03)$.

In addition, the mean muscle force of patients during the first day after the surgery in the FNB group was significantly lower than that in the IPNB

\begin{tabular}{|c|c|c|c|}
\hline \multirow{2}{*}{ Variables } & \multicolumn{2}{|c|}{ Groups } & \multirow{2}{*}{ P-value } \\
\hline & Infrapatellar & Femoral nerve & \\
\hline $\begin{array}{l}\text { Age(year) } \\
\text { Mean } \pm S D\end{array}$ & $34.15 \pm 6.42^{+}$ & $33.11 \pm 6.18$ & 0.429 \\
\hline $\begin{array}{l}\text { Gender } \\
\text { Male } \\
\text { Female }\end{array}$ & $\begin{array}{l}6(13 \%)^{\#} \\
40(87 \%)\end{array}$ & $\begin{array}{l}10(21.7 \%) \\
36(78.6 \%)\end{array}$ & 0.271 \\
\hline $\begin{array}{l}\text { Body mass index }\left(\mathbf{k g} / \mathbf{m}^{2}\right) \\
\text { Mean } \pm S D\end{array}$ & $26.16 \pm 1.94$ & $26.1 \pm 2.92$ & 0.752 \\
\hline $\begin{array}{l}\text { Duration of Surgery (hours) } \\
\text { Mean } \pm S D\end{array}$ & $123.26 \pm 14.46$ & $126.84 \pm 14.99$ & 0.246 \\
\hline
\end{tabular}

\begin{tabular}{lccc}
\hline \multicolumn{2}{l}{ Table 2. Comparison of pain scores at rest bweteen the two groups } \\
\cline { 2 - 3 } Time Measurement & \multicolumn{2}{c}{ Groups } & \multirow{2}{*}{ P-value } \\
\cline { 2 - 3 } & Infrapatellar & Femoral nerve & 0.139 \\
\hline Recovery & $3.47 \pm 0.58^{+}$ & $3.67 \pm 0.66$ & 0.001 \\
1 h after surgery & $2.84 \pm 0.41$ & $2.41 \pm 0.58$ & 0.001 \\
3 h after surgery & $2.5 \pm 0.5$ & $2.17 \pm 0.38$ & 0.843 \\
6 h after surgery & $2.45 \pm 0.5$ & $2.47 \pm 0.54$ & 0.592 \\
12 h after surgery & $2.89 \pm 0.64$ & $2.95 \pm 0.51$ & 0.241 \\
24 h after surgery & $3.11 \pm 0.67$ & $2.95 \pm 0.55$ & \\
\hline
\end{tabular}

$+:$ Mean \pm SD

\begin{tabular}{lccc}
\hline \multicolumn{2}{l}{ Table 3. Comparison of pain scores at flexion between the two groups } \\
\cline { 2 - 3 } \multicolumn{2}{c}{ Time Measurement } & \multicolumn{3}{c}{ Groups } & \multirow{2}{*}{ P-value } \\
\cline { 2 - 3 } & Infrapatellar & Femoral nerve & 0.294 \\
\hline Recovery & $5.74 \pm 0.77^{+}$ & $5.56 \pm 0.8$ & 0.003 \\
1 h after surgery & $4.58 \pm 0.65$ & $4.17 \pm 0.64$ & 0.322 \\
3 h after surgery & $4.08 \pm 0.55$ & $3.97 \pm 0.49$ & 0.74 \\
6 h after surgery & $4.28 \pm 0.58$ & $4.33 \pm 0.66$ & 0.098 \\
12 h after surgery & $4.84 \pm 0.94$ & $4.56 \pm 0.65$ & 0.069 \\
\hline 24 h after surgery & $4.78 \pm 1.03$ & $4.37 \pm 0.85$ & \\
\hline
\end{tabular}

$+:$ Mean \pm SD

\begin{tabular}{|c|c|c|c|}
\hline \multirow{2}{*}{ Time Measurement } & \multicolumn{2}{|c|}{ Groups } & \multirow{2}{*}{ P-value } \\
\hline & Infrapatellar & Femoral nerve & \\
\hline Recovery & $2.28 \pm 0.54^{+}$ & $2.11 \pm 0.7$ & 0.189 \\
\hline $1 \mathrm{~h}$ after surgery & $2.93 \pm 0.71$ & $3.54 \pm 0.72$ & 0.001 \\
\hline $3 \mathrm{~h}$ after surgery & $3.78 \pm 0.47$ & $3.89 \pm 0.31$ & 0.194 \\
\hline $6 \mathrm{~h}$ after surgery & $3.91 \pm 0.28$ & $3.95 \pm 0.2$ & 0.404 \\
\hline $12 \mathrm{~h}$ after surgery & $3.63 \pm 0.53$ & $3.71 \pm 0.45$ & 0.402 \\
\hline $24 \mathrm{~h}$ after surgery & $3.21 \pm 0.51$ & $3.32 \pm 0.52$ & 0.315 \\
\hline
\end{tabular}




\begin{tabular}{lccc}
\hline \multicolumn{2}{l}{ Table 5. Comparison of muscle force score between the two groups } \\
\cline { 2 - 3 } Time Measurement & \multicolumn{2}{c}{ Group } & \multirow{2}{*}{ P-value } \\
\cline { 2 - 3 } 1 h after surgery & $1.21 \pm 0.41^{+}$ & Femoral nerve & 0.001 \\
3 h after surgery & $2.56 \pm 0.5$ & $1 \pm 0$ & 0.001 \\
6 h after surgery & $3.28 \pm 0.45$ & $1.11 \pm 0.31$ & 0.001 \\
12 h after surgery & $4.45 \pm 0.54$ & $2.34 \pm 0.52$ & 0.001 \\
24 h after surgery & $5 \pm 0$ & $2.91 \pm 0.28$ & 0.001 \\
\hline
\end{tabular}

$+:$ Mean \pm SD

Table 6. Comparison of the first analgesic request time and the prescribed dose of opioids during the first and second $12 \mathrm{~h}$ bwteen the two groups

\begin{tabular}{lccc}
\hline \multirow{2}{*}{ Variables } & \multicolumn{2}{c}{ Groups } & \multirow{2}{*}{ P-value } \\
\cline { 2 - 3 } & Infrapatellar & Femoral nerve & \\
\hline Time required for the first analgesic request (hour) & $3.39 \pm 0.49^{+}$ & $3.76 \pm 0.52$ & 0.001 \\
Used opioids during the first 12 $\mathbf{h}(\boldsymbol{\mu g})$ & $97.22 \pm 9.97$ & $61.52 \pm 10.48$ & 0.429 \\
Used opioids during the second $\mathbf{~} \mathbf{h}(\boldsymbol{\mu g})$ & $154.44 \pm 8.42$ & $100.32 \pm 10.02$ & 0.429 \\
\hline$+:$ Mean $+S D$ & &
\end{tabular}

group $(\mathrm{P}<0.05)$ (Table 5). Moreover, the FNB group obtained a higher mean time required for the first dose of analgesic request, compared to the IPNB group $(\mathrm{P}<0.05)$. The mean dose of used opioids during the first and second $12 \mathrm{~h}$ in the FNB group was significantly lower than that in the IPNB group $(\mathrm{P}<0.05) \quad($ Table 6$)$. In the second $12 \mathrm{~h}$, the used opioid was significantly higher in both groups $(\mathrm{P}<0.05)$.

\section{Discussion}

Arthroscopic ACL reconstruction is one of the most common orthopedic procedures. Multiple protocols have been utilized for the pain relief following this surgery while trying to keep quadriceps muscle force. In this regard, the present study was conducted to compare the effects of FNB and IPNB in terms of reduction in pain severity, patient satisfaction, and maintenance of muscle force. It was indicated that FNB had superiority to IPNB in terms of reduction in pain score at rest, knee flexion (during early hours after the procedure), and patient satisfaction score. The femoral group required needed less analgesia after surgery; however, the use of opioids was higher in the second $12 \mathrm{~h}$ after the surgery, which may be due to the termination of block duration time. The IPNB had superiority to FNB in terms of the maintenance of the quadriceps force, which is in line with the findings of other studies. As previously noted, the utilization of the FNB leads to some complications, such as the delayed return of quadriceps muscle function (15-21). This complication is sometimes observed up to six months following the FNB (22, 23). The delayed return of muscle force in the long term can lead to patient dissatisfaction. Therefore, a balance should be maintained between the good analgesia outcome of the FNB and its complications after ACL surgery.

According to a study conducted by Marit
Lundblad et al., patients experienced less pain and improvements in sleep after ACL arthroscopy surgery with IPNB. It should be mentioned that this study did not compare the groups regarding muscle force (30). In the current study, the reduction of pain in the FNB group was significantly more noticeable during the early hours after the surgery; however, the IPNB group showed improvements in muscle force.

In a study performed by Rahimzadeh et al., the analgesic impact of the FNB and the adductor canal block was compared after arthroscopic knee surgery. The results revealed a decrease in the mean VAS scores from 5.6 to 4 immediately after both blocks. The pain scores three hours after the block were reduced to 2 and 3.4 in the FNB and adductor block groups, respectively. This study indicated that patients in the FNB group required analgesics less than the other group; in addition, they showed a higher satisfaction rate. It is worth mentioning that this study mentioned no muscle force (31).

In the same vein, Ahl concluded that the patients with adductor canal block had higher VAS scores and morphine consumption, compared to the FNB group. Nonetheless, the adductor group obtained less muscle weakness, which was in line with the results of the current study (32).

Magnussen et al. compared the impacts of FNB and placebo block; moreover, they revealed that the patients who underwent FNB obtained a mean quadriceps femoris-limb symmetry index that was $13.4 \%$ lower than that in the control group. In addition, they had a poorer knee injury and osteoarthritis outcome scores six weeks after the surgery, compared to controls.

This decline in quadriceps force was quite similar to that in the present study following FNB (33). Guirro et al. compared the patients who underwent spinal anesthesia and FNB with a group that only had spinal anesthesia. According to the results, pain control after surgery was more efficient in the first 
group, compared to the other group. However, there was no difference between the two groups in terms of tramadol requests for pain relief (34).

Based on the results of the present study, it seems that FNB is associated with a greater pain relief and satisfaction score in patients undergoing arthroscopic ACL repair, compared to the IPNB technique. However, a further delay in the recovery of quadriceps muscle force is evident in the FNB technique which did not lead to dissatisfaction in our patients.

Regarding the limitations of this study, one can name the limited follow-up time and the number of patients. Therefore, it is recommended that multicentric studies be conducted with a larger sample size for a longer time.

\section{Conclusion}

The FNB is associated with greater pain relief and satisfaction in patients undergoing arthroscopic ACL reconstruction, compared to the IPNB technique; however, a further delay was observed in the return of quadriceps force.

\section{Acknowledgments}

The authors would like to thank the Rasool Akram Medical Complex Clinical Research Development Center (RCRDC) for its technical assists.

\section{Footnotes}

Authors' Contribution: Study concept and design: SHRF and PR; analysis and interpretation of data: PR and SSK; drafting of the manuscript SHRF, FI, and PR; critical revision of the manuscript for important intellectual content: SHRF, PR, and SSK; statistical analysis: SHRF, PR, KH, and AS

Conflict of Interests: The authors declare that they have no competing interests.

Ethical Approval: The study protocol was approved by the Ethics Committee of Iran University of Medical Sciences, Tehran, Iran (IR.IUMS.FMD.REC.1398.377) and registered in the Iranian Registry of Clinical Trials (IRCT20120814010599N22).

Funding/Support: This study did not receive any specific grant from funding agencies in the public, commercial, or not-for-profit sectors.

Informed consent: Informed consent was obtained from the patients.

\section{References}

1. Duarte VM, Fallis WM, Slonowsky D, Kwarteng K, Yeung CK. Effectiveness of femoral nerve blockade for pain control after total knee arthroplasty. J Perianesth Nurs. 2006;21(5):311-6. doi: 10.1016/j.jopan.2006.05.011. [PubMed: 17027440].

2. Singelyn FJ, Ferrant T, Malisse MF, Joris D. Effects of intravenous patient-controlled analgesia with morphine, continuous epidural analgesia, and continuous femoral nerve sheath block on rehabilitation after unilateral total-hip arthroplasty. RegAnesth Pain Med. 2005;30(5):452-7. doi: 10.1016/j.rapm.2005.05.008. [PubMed: 16135349].

3. Jaeger P, Nielsen ZJ, Henningsen MH, Hilsted KL, Mathiesen O, Dahl JB. Adductor canal block versus femoral nerve block and quadriceps strength: a randomized, double-blind, placebocontrolled, crossover study in healthy volunteers. Anesthesiology. 2013;118(2):409-15. doi: 10.1097/ALN.0b013e318279fa0b. [PubMed: 23241723].

4. Jenstrup MT, Jaeger P, Lund J, Fomsgaard JS, Bache S, Mathiesen O, et al. Effects of adductor-canal-blockade on pain and ambulation after total knee arthroplasty: a randomized study. Acta Anaesthesiol Scand. 2012;56(3):357-64. doi: 10.1111/j.1399-6576.2011.02621.x. [PubMed: 22221014].

5. Manickam B, Perlas A, Duggan E, Brull R, Chan VW, Ramlogan R. Feasibility and efficacy of ultrasound-guided block of the saphenous nerve in the adductor canal. Reg Anesth Pain Med. 2009;34(6):578-80. doi: 10.1097/aap.0b013e3181bfbf84. [PubMed: 19916251].

6. Memtsoudis SG, Yoo D, Stundner O, Danninger T, Ma Y, Poultsides L, et al. Subsartorial adductor canal vs femoral nerve block for analgesia after total knee replacement. Int Orthop. 2015;39(4):673-80. doi: 10.1007/s00264-014-2527-3. [PubMed: 25297681].

7. Wang H, Boctor B, Verner J. The effect of single-injection femoral nerve block on rehabilitation and length of hospital stay after total knee replacement. Reg Anesth Pain Med. 2002;27(2):139-44. doi: 10.1053/rapm.2002.29253. [PubMed: 11915059].

8. Saranteas T, Anagnostis G, Paraskeuopoulos T, Koulalis D, Kokkalis Z, Nakou M, et al. Anatomy and clinical implications of the ultrasound-guided subsartorial saphenous nerve block. Reg Anesth Pain Med. 2011;36(4):399-402. doi: 10.1097/AAP.0b013e318220f172. [PubMed: 21697687].

9. Kasibhatla RD, Russon K. Femoral nerve blocks. J Perioper Pract. 2009;19(2):65-9. doi: 10.1177/175045890901900204. [PubMed: 19266878].

10. e Souza RD, Correa CH, Henriques MD, de Oliveira CB, Nunes TA, Gomez RS. Single-injection femoral nerve block with $0.25 \%$ ropivacaine or $0.25 \%$ bupivacaine for postoperative analgesia after total knee replacement or anterior cruciate ligament reconstruction. J Clin Anesth. 2008;20(7):521-7. doi: 10.1016/j.jclinane.2008.05.016. [PubMed: 19019663].

11. Myer GD, Paterno MV, Ford KR, Hewett TE. Neuromuscular training techniques to target deficits before return to sport after anterior cruciate ligament reconstruction.J Strength Cond Res.2008;22(3):987-1014. 10.1519/JSC.0b013e31816a86cd. [PubMed: 18438211].

12. Myer GD, Paterno MV, Ford KR, Quatman CE, Hewett TE. Rehabilitation after anterior cruciate ligament reconstruction: criteriabased progression through the return-to-sport phase. J Orthop Sports Phys Ther. 2006;36(6):385-402. doi: 10.2519/jospt.2006.2222. [PubMed: 16776488].

13. Hartigan EH, Zeni J, Di Stasi S, Axe MJ, Snyder-Mackler L. Preoperative predictors for noncopers to pass return to sports criteria after ACL reconstruction. J Appl Biomech. 2012;28(4): 366-73. doi: 10.1123/jab.28.4.366. [PubMed: 22983930].

14. Kvist J. Rehabilitation following anterior cruciate ligament injury: current recommendations for sports participation. Sports Med. 2004;34(4):269-80. doi: 10.2165/00007256200434040-00006. [PubMed: 15049718].

15. Edkin BS, Spindler KP, Flanagan JF. Femoral nerve block as an alternative to parenteral narcotics for pain control after anterior cruciate ligament reconstruction. Arthroscopy. 1995;11(4): 404-9. doi: 10.1016/0749-8063(95)90191-4. [PubMed: 7575871].

16. Frost S, Grossfeld S, Kirkley A, Litchfield B, Fowler P, Amendola A. The efficacy of femoral nerve block in pain reduction for outpatient hamstring anterior cruciate ligament reconstruction: a double-blind, prospective, randomized trial. Arthroscopy. 2000;16(3):243-8. doi: 10.1016/s0749-8063(00)90047-1. [PubMed: 10750003].

17. Mehdi SA, Dalton DJ, Sivarajan V, Leach WJ. BTB ACL 
reconstruction: femoral nerve block has no advantage over intraarticular local anaesthetic infiltration. Knee Surg Sports Traumatol Arthrosc. 2004;12(3):180-3. doi: 10.1007/s00167003-0464-6. [PubMed: 14740155].

18. Pournajafian, AR, Ghodraty, MR, Faiz, SHR, Rahimzadeh P, Goodarzynejad H, Dogmehchi E. Comparing glidescope video laryngoscope and macintosh laryngoscope regarding hemodynamic responses during orotracheal intubation: A randomized controlled trial. Iran Red Crescent Med J. 2014;16(4):e12334. doi: 10.5812/ircmj.12334. [PubMed: 24910788].

19. Rahimzadeh, P., Faiz, S.H.R., Ziyaeifard, M., Niknam, K. Rahimzadeh P, Faiz SHR, Ziyaeifard M, Niknam K. Effectiveness of adding ketamine to ropivacaine infusion via femoral nerve catheter after knee anterior cruciate ligament repair. J Res Med Sci. 2013;18(8):632-6. [PubMed: 24379836].

20. Atchabahian A, Brown AR. Postoperative neuropathy following fascia iliaca compartment blockade. Anesthesiology. 2001; 94(3):534-6. doi: 10.1097/00000542-200103000-00029. [PubMed: 11374619].

21. Cuvillon P, Ripart J, Lalourcey L, Veyrat E, L'Hermite J, Boisson $C$, et al. The continuous femoral nerve block catheter for postoperative analgesia: bacterial colonization, infectious rate and adverse effects. Anesth Analg. 2001;93(4): 1045-9. doi: 10.1097/00000539-200110000-00050. [PubMed: 11574381].

22. Krych A, Arutyunyan G, Kuzma S, Levy B, Dahm D, Stuart M. Adverse effect of femoral nerve blockade on quadriceps strength and function after ACL reconstruction. J Knee Surg. 2015;28(1): 83-8. doi: 10.1055/s-0034-1371769. [PubMed: 24622910].

23. Luo TD, Ashraf A, Dahm DL, Stuart MJ, McIntosh AL. Femoral nerve block is associated with persistent strength deficits at 6 months after anterior cruciate ligament reconstruction in pediatric and adolescent patients. Am J Sports Med. 2015; 43(2):331-6. doi: 10.1177/0363546514559823. [PubMed: 25466410]

24. Koh IJ, Chang CB, Seo ES, Kim SJ, Seong SC, Kim TK. Pain management by periarticular multimodal drug injection after anterior cruciate ligament reconstruction: a randomized, controlled study. Arthroscopy. 2012;28(5):649-57. doi: 10.1016/j.arthro.2011.10.015. [PubMed: 22281194].

25. Rosaeg OP, Krepski B, Cicutti N, Dennehy KC, Lui AC, Johnson DH. Effect of preemptive multimodal analgesia for arthoscopic knee ligament repair. Reg Anesth Pain Med. 2001;26(2):12530. doi: 10.1053/rapm.2001.20982. [PubMed: 11251135].
26. McCarty EC, Spindler KP, Tingstad E, Shyr Y, Higgins M. Does intraarticular morphine improve pain control with femoral nerve block after anterior cruciate ligament reconstruction? Am J Sports Med. 2001;29(3):327-32. doi: 10.1177/0363546 5010290031301. [PubMed: 11394604].

27. Prodromos CC, Han Y, Rogowski J, Joyce B, Shi K. A metaanalysis of the incidence of anterior cruciate ligament tears as a function of gender, sport, and a knee injury-reduction regimen. Arthroscopy. 2007;23(12):1320-5.e6. doi: 10.1016/ j.arthro.2007.07.003. [PubMed: 18063176].

28. Frank CB, Jackson DW. The science of reconstruction of the anterior cruciate ligament. J Bone Joint Surg Am. 1997; 79(10):1556-76. doi: 10.2106/00004623-199710000-00014. [PubMed: 9378743].

29. Jansen TK, Miller BE, Arretche N, Pellegrini JE.. Will the addition of a sciatic nerve block to a femoral nerve block provide better pain control following anterior cruciate ligament repair surgery? AANA J. 2009;77(3):213-8. [PubMed: 19645171].

30. Lundblad M, Forssblad M, Eksborg S, Lönnqvist PA. Ultrasound-guided infrapatellar nerve block for anterior cruciate ligament repair: a prospective, randomised, doubleblind, placebo-controlled clinical trial. Eur J Anaesthesiol. 2011;28(7):511-8. doi: 10.1097/EJA.0b013e32834515ba. [PubMed: 21455076].

31. Rahimzadeh P, Faiz HR, Imani F, Hobika GG, Abbasi A, Nader ND. Relieving pain after arthroscopic knee surgery: ultrasound-guided femoral nerve block or adductor canal block? Turk J Anaesthesiol Reanimation. 2017;45(4):218-24. doi: 10.5152/TJAR.2017.00868. [PubMed: 28868169].

32. El Ahl MS. Femoral nerve block versus adductor canal block for postoperative pain control after anterior cruciate ligament reconstruction: A randomized controlled double blind study. Saudi J Anaesth. 2015;9(3):279-82. doi: 10.4103/1658354X.154708. [PubMed: 26240546].

33. Magnussen RA, Pottkotter K, Di Stasi S, Paterno MV, Wordeman SC, Schmitt LC, et al. Femoral nerve block after anterior cruciate ligament reconstruction. I Knee Surg. 2017;30(04):323-8. doi: 10.1055/s-0036-1584538. [PubMed: 27362929].

34. do Prado Guirro ÚB, Tambara EM, Munhoz FR. Femoral nerve block: assessment of postoperative analgesia in arthroscopic anterior cruciate ligament reconstruction. Braz J Anesthesiol. 2013;63(6):483-91. doi: 10.1016/j.bjane.2013.09.001. [PubMed: 24565346]. 